Schulich School of Law, Dalhousie University

Schulich Law Scholars

Research Papers, Working Papers, Conference

Papers

Faculty Scholarship

$6-29-2013$

\title{
III-Informed Consent? A Content Analysis of Physical Risk Disclosure in School-Based HPV Vaccine Programs
}

Jocelyn Downie

Dalhousie University - Schulich School of Law, jocelyn.downie@dal.ca

Noni MacDonald

Dalhousie University, noni.macdonald@dal.ca

Francoise Baylis

Dalhousie University, francoise.baylis@dal.ca

Audrey Steenbeek

Dalhousie University, a.steenbeek@dal.ca

Mary Appleton

Dalhousie University, mary.appleton@iwk.nshealth.ca

Follow this and additional works at: https://digitalcommons.schulichlaw.dal.ca/working_papers

\section{Recommended Citation}

Downie, Jocelyn; MacDonald, Noni; Baylis, Francoise; Steenbeek, Audrey; and Appleton, Mary, "III-Informed Consent? A Content Analysis of Physical Risk Disclosure in School-Based HPV Vaccine Programs" (2013). Research Papers, Working Papers, Conference Papers. 21.

https://digitalcommons.schulichlaw.dal.ca/working_papers/21

This Working Paper is brought to you for free and open access by the Faculty Scholarship at Schulich Law Scholars. It has been accepted for inclusion in Research Papers, Working Papers, Conference Papers by an authorized administrator of Schulich Law Scholars. For more information, please contact hannah.steeves@dal.ca. 


\title{
Ill-Informed Consent? A Content Analysis of Physical Risk Disclosure in School-Based HPV Vaccine Programs
}

\author{
Audrey Steenbeek, Ph.D., R.N., ${ }^{1}$ Noni MacDonald, M.D., M.S.C., ${ }^{2,6}$ Jocelyn Downie, S.J.D., ${ }^{3}$
} Mary Appleton, B.A., and Françoise Baylis, Ph.D.'

${ }^{1}$ School of Nursing \& Faculty of Medicine, Department of Community Health \& Epidemiology, Dalhousie University, Halifax, Nova Scotia;

${ }^{2}$ Department of Health Policy Translation, IWK Health Centre, Canadian Center for Vaccinology, Halifax, Nova Scotia; ${ }^{3}$ Faculties of Larw E Medicine E Schlich School of Law, Dalhousie University, Halifax, Nova Scotia; ${ }^{4}$ IWK Health Centre, Canadian Centre of Vaccinology, Halifax, Nova Scotia; ${ }^{5}$ Departments of Bioethics \& Philosopy, Dalbousie University, Halifax, Nova Scotia; and ${ }^{6}$ Department of Pediatrics, Faculty of Medicine, Dalhousie University, Halifax, Nova Scotia

\section{Correspondence to:}

Dr. Audrey Steenbeek, Associate Professor, Dalhousie University, School of Nursing, 1459 Oxford Street, Halifax, NS, Canada B3J 4R2.

E-mail:a.steenbeek@dal.ca

\begin{abstract}
Objectives: This study examines the accuracy, completeness, and consistency of human papilloma virus (HPV) vaccine related physical risks disclosed in documents available to parents, legal guardians, and girls in Canadian jurisdictions with school-based HPV vaccine programs. Design and Sample: We conducted an online search for program related HPV vaccine risk/benefit documents for all 13 Canadian jurisdictions between July 2008 and May 2009 including followup by email and telephone requests for relevant documents from the respective Ministries or Departments of Health. The physical risks listed in the documents were compared across jurisdictions and against documents prepared by the vaccine manufacturer (Merck Frosst Canada), the National Advisory Committee on Immunization (NACI), the Society of Obstetricians and Gynecologists of Canada (SOGC), and a 2007 article in Maclean's Magazine. Results: No jurisdiction provided the same list of vaccine related physical risks as any other jurisdiction. Major discrepancies were identified. Conclusions: Inaccurate, incomplete, and inconsistent information can threaten the validity of consent/authorization and potentially undermine trust in the vaccine program and the vaccine itself. Efforts are needed to improve the quality, clarity, and standardization of the content of written documents used in schoolbased HPV vaccine programs across Canada.
\end{abstract}

Key words: authorization, HPV vaccine risks, informed consent, school.

\section{Background}

The human papillomavirus (HPV) is one of the most prevalent types of sexually transmitted viral infections in Canada and, globally with an estimated $75-80 \%$ of all sexually active young adults contracting at least one HPV infection in their lifetime (Bekkers, Massuger, Bulten, \& Melchers, 2004; Health Canada, 2009; Lenselink et al., 2009). HPV infection has been linked to genital warts and cervical cancer (Health Canada, 2009; National Cancer Institute, 2009). In Canada, the quadrivalent recombinant HPV vaccine, Gardasil ${ }^{\mathrm{TM}}$ (GardasilTM, 2008) that prevents infection from two high risk strains of HPV (16 and 18) that cause approximately $70 \%$ of cervical cancers and two low risk strains (6 and 11) that cause genital warts was approved by Health Canada in 2006 (Health Canada, 2007). In February 2007, the National Advisory Committee on Immunization (NACI) recommended this vaccine for women aged 9-26 (NACI, 2007). NACI is a committee of experts in pediatrics, infectious diseases, immunology, medical microbiology, 
internal medicine, and public health that is tasked to provide the Canadian government through the Public Health Agency of Canada (PHAC) with "ongoing and timely medical, scientific, and public-health advice relating to immunization" (National Advisory Committee on Immunization, 2009). In March 2007, the federal government designated $\$ 300$ million over 3 years to support provincial and territorial HPV vaccine programs (Department of Finance Canada, 2007). At the time this review was conducted, Gardasil $^{\mathrm{TM}}$ was the only approved HPV vaccine in Canada.

In the fall of 2007, several of the Canadian provinces used these federal funds to introduce publicly funded school-based HPV vaccine programs for girls. In Canada, for well over a decade, school-based (i.e., not school entry) vaccine programs, have been used to deliver provincial/territorial government funded vaccine programs for $\mathrm{HBV}$ to middle school children at their respective schools (Patrick et al., 2003). These (and subsequent) HPV vaccine programs in other provinces and territories were criticized on several fronts including: vaccine safety, the appropriateness of the target population (by age or school grade), allocation of resources to this particular vaccine, and the potential effects on the initiation of sexual activity and promiscuity (Priest, 2006; Lippman, Melnychuk, Shimmin, \& Boscoe 2007; MacDonald, Stanbrook, \& Hébert, 2008). Within this debate, little attention has been paid to the quality of the consent/authorization processes in these school-based HPV vaccine programs.

In provincial/territorial school-based vaccine programs, it is common practice to ask students to deliver written documents about the immunizations to their parent(s) or legal guardian(s) and to return completed consent/authorization forms to the school prior to the student receiving the vaccine (Cawley, Hull, \& Rousculp, 2010). This practice is thought to be cost-effective and efficient (Cawley et al., 2010). To date, concerns about consent in school-based programs have focused on issues around maximizing return of the consent form, not on ethical issues related to the quality of consents/ authorizations obtained (Cawley et al., 2010). There are, however, a number of such issues. For example, in school-based vaccine programs, there may be no direct interpersonal contact between the immunizer and the parent(s) or legal guardian(s) who provide the consent/authorization, and thus limited opportunity to directly ask and receive answers to questions. The written information provided to the parent(s) or legal guardian(s) may differ from the written and verbal information provided to the students at school, at the time when they are asked to deliver the written documents. Additional information about potential harms and benefits may be provided at the time of vaccination, when the parent(s) or legal guardian(s) who have provided consent/authorization likely are not present, which could put the validity of the original consent/authorization into question. These are significant ethical challenges for which there are no easy solutions. An important first step, however, is to ensure that the parents, legal guardians, and students receive accurate, complete, and consistent written information on which they can make an informed choice.

\section{Research Question}

Using the NACI HPV statement (NACI, 2007) as the reference, do provincial/territorial government departments provide: accurate, complete, and consistent HPV vaccine-related physical risk information to parents/guardians and girls in Canadian jurisdictions? How does provincial/territorial government department HPV vaccine-related physical risk information compare to what is provided by the vaccine manufacturer, SOGC, and by the Gulli (2007) article?

\section{Methods}

\section{Design and sample}

This study employed an observational, descriptive, content analysis design to review provincial government documents produced for the public (i.e., pamphlets, brochures, fact sheets and Frequently Asked Questions [FAQs]) that contained information about the physical risks associated with the HPV vaccine, and that would have been accessed by parents/guardians and girls in determining consent for HPV vaccine to be given in school-based programs. Some of the reviewed documents included signature lines for consent but a comprehensive collection of "consent forms" were not collected from individual health units because of time constraints. 


\section{Measures}

A "Google" search of school-based HPV vaccine programs for each Canadian province (ten provinces and three territories) was conducted between July 2008 and May 2009 to identify relevant documents (print and web-based); "HPV vaccine X" was used as the search term, whereby " $\mathrm{X}$ " was the name of the Canadian province or territory being searched (e.g., HPV vaccine British Columbia). The "Google" search engine was used as it is the most frequently used search engine by the lay public (Hitwise, 2011). In addition, where information had not been accessible, emails were sent to the provincial Ministries or Departments of Health by one of the authors (MA), requesting copies of any HPV schoolbased vaccine-related documents (i.e., pamphlets, FAQs, information sheets) typically distributed to parents, legal guardians, or girls. If both the online search and e-mail requests were unsuccessful in obtaining relevant documents (i.e., within a period of about 2 months), a follow-up telephone call was made requesting the relevant documents.

\section{Analytic strategy}

The review for the accuracy, completeness, and consistency of information provided on HPV vaccine was narrowed to the disclosure of physical risks associated with HPV vaccine in public documents collected between July 2008 and May 2009. To ensure consistency, the documents (Table 1) that cited risks were reviewed independently by three of the authors (AS, NM \& MA) for category placement, with any discrepancies discussed and resolved. The risks disclosed in the provincial documents were compared across jurisdictions and to documents prepared by (i) Merck Frosst Canada (MFC) (the manufacturer of Gardasil' ${ }^{\mathrm{TM}}$, Merck Frosst Canada [MFC], Kirkland, QC, Canada) in the product monograph (Gardasil TM Product Monograph, 2008) (in the form and with the content required by Health Canada; Health Canada, 2007) and the consumer product information, (ii) NACI in their statement on HPV vaccine published in the Canada Communicable Disease Report (NACI, 2007), and (iii) SOGC in the Canadian Consensus Guidelines on HPV developed through unrestricted educational grants from several pharmaceutical companies, including Merck Frosst, published in the Journal of Obstetrics and Gynaecology Canada, and posted on www.hpvinfo.ca, the SOGC devel-
TABLE 1. HPV Vaccine Information Available to the General Public by Province

\begin{tabular}{|c|c|c|c|c|c|}
\hline \multirow[b]{2}{*}{ Province } & \multicolumn{5}{|c|}{ Source Documents } \\
\hline & Pamphlet & $\begin{array}{l}\text { Fact } \\
\text { Sheet }\end{array}$ & FAQs & Brochure & Total \\
\hline $\begin{array}{l}\text { British } \\
\text { Columbia }\end{array}$ & & $\mathrm{X}(1)$ & $X(1)$ & & 2 \\
\hline Alberta & $X(1)$ & $X(1)$ & $X(1)$ & & 3 \\
\hline Saskatchewan & & $X(1)$ & & & 1 \\
\hline Manitoba & & & $X(4)$ & & 4 \\
\hline Ontario & & & $\mathrm{X}(3)$ & $\mathrm{X}(1)$ & 4 \\
\hline Quebec & & & $\mathrm{X}(2)$ & $\mathrm{X}(1)$ & 3 \\
\hline $\begin{array}{l}\text { New } \\
\text { Brunswick }\end{array}$ & $X(1)$ & $\mathrm{X}(1)$ & & $\mathrm{X}(1)$ & 3 \\
\hline Nova Scotia & & & & $\mathrm{X}(1)$ & 1 \\
\hline Newfoundland & & & $\mathrm{X}(1)$ & & 1 \\
\hline $\begin{array}{l}\text { Prince } \\
\text { Edward } \\
\text { Island }\end{array}$ & & $X(1)$ & & & 1 \\
\hline
\end{tabular}

Note. FAQs,Frequently Asked Questions.

$\mathrm{X}$, presence of select item.

(), number of specific item retrieved.

This Table only includes information readily available to the general public via the Internet, or voluntarily provided by provincial Ministries or Departments via e-mail and/or phone requests. Yukon, Nunavut \& Northwest Territories had not initiated school-based HPV programs at the time of this study.

oped HPV website funded by Merck Frosst (A.B. Lalonde, personal communication with JD, 2010). As well, the 2007 article by Cathy Gulli (2007) in Maclean's magazine (MAC) "Our girls are not guinea pigs" was included in the comparison, not because it was an authoritative source but rather, as it was a readily accessible public source of information, that garnered considerable media attention across Canada when the first HPV provincial school-based vaccination programs were being implemented. The authors speculated that this particular article may have influenced (both positively and negatively) parent's/legal guardian's and girl's decision to participate in the school-based HPV vaccination programs. It is important to note that during the study period Gardisil ${ }^{\mathrm{TM}}$ was the only HPV vaccine used for all the school-based programs in Canadian jurisdictions.

\section{Data organization}

All retrieved information was organized by: (i) source: Merck Frosst Canada (GardasilTM, 2008); NACI (NACI, 2007), SOGC (Shier \& Bryson, 2007), 
Maclean's magazine (Gulli, 2007) and each of the ten provinces (ii) document type, and (iii) physical risks (i.e., local, minor systemic, and major systemic). For the sake of consistency and ease of comparison, a condensed list of vaccine-related physical risks was generated using the World Health Organization (WHO) adverse reaction terminology (World Health Organization, 2005). For example, following the WHO terminology, itchiness in one document and pruritus in another document would both be listed as "pruritis." Terminology was further condensed by combining similar risks (e.g., fever $\geq 37.8-39^{\circ} \mathrm{C}$ and fever $>39{ }^{\circ} \mathrm{C}$ as fever). These data were then collated into a table (Table 2) that summarized differences across the documents reviewed. A further table (Table 3) was developed that used NACI as the standard against which the other documents were compared.

\section{Results}

The documents collected and collated from provincial government departments (i.e., the departments that oversee the school-based clinics and develop the HPV-related material) are noted in Table 1. Pamphlets, fact sheets, FAQs and brochures that could be used to inform the consent process were collected and compared for disclosure of physical risks. Consent forms were not consistently available and when available, appeared in various formats that may or may not have included disclosure of risks. If information was not available online, e-mails and phone calls were made to the respected provincial/ territorial health department for assistance in retrieving documentation. Within a couple of months, all provincial government contacts had responded to requests for relevant documents.

At least one HPV vaccine-related information document was obtained from each of the ten provinces. No information about vaccine-related risks was available in May 2009 (when data collection was completed) from the three territories (Yukon, Nunavut, or Northwest Territories) as these jurisdictions had not yet initiated their HPV vaccination programs.

A summary of the HPV vaccine-related physical risks noted in each of the ten provinces is presented in Table 2 as well as those identified by, Merck Frosst Canada, NACI, SOGC, and the 2007 Gulli article in Maclean's magazine. Significant differences were noted in the accuracy, completeness, and consistency in the information on these physical risks of HPV vaccination both nationally and interprovincially. The professional organization "SOGC", listed far fewer risks than those identified by the manufacturer and by NACI. While there was substantial similarity with respect to local risks, there were major discrepancies for minor and major systemic risks. The SOGC stated that "studies have shown no serious side effects attributed to the vaccine" (Shier \& Bryson, 2007), while Merck Frosst Canada reported ten minor and major systemic risks and NACI listed nine (Table 3).

With respect to accuracy, completeness, and consistency of information provided by the ten provinces, all ten cited at least three of the local risks listed by NACI (Table 2). Beyond this, five of the ten provinces included the fourth local risk identified by NACI (i.e., pruritus). Regarding minor and major systemic risks, significant differences were noted among the provinces and with those cited by NACI (Table 2). Not one province cited the same set of minor or major systemic risks. For example, Manitoba listed lymphadenopathy "swollen glands" while NACI did not cite this; the manufacturer did cite this risk in its consumer information document but not in the product monograph.

Clarity of language was also a problem in making comparisons between all documents. For example, NACI did not comment specifically on anaphylaxis stating "There was no evidence that vaccination resulted in allergic reactions or immunemediated diseases"( NACI, 2007) but did note that bronchospasm was possibly related (NACI, 2007). Five out of ten provinces listed anaphylaxis as a rare risk event (Table 2). There was also a lack of clarity with interpretation of data presented within NACI's statement on HPV (NACI, 2007). NACI's statement presented data on systemic adverse events following immunization in their table seven, stating that these represented "the vaccine-related adverse experiences that were observed among female recipients of Gardasil $^{\mathrm{TM}}$ at a frequency of at least $1.0 \%$ and at a greater frequency than observed among female placebo recipients" (NACI, 2007). NACI reported $4.2 \%$ nausea in HPV vaccine recipients versus $4.1 \%$ in aluminum and non aluminum containing placebo vaccine recipients (NACI, 2007) but were silent on whether the difference in rate is clinically meaningful. Seven of ten provinces listed nausea as a vac- 
TABLE 2. Selected HPV Vaccine-related Physical Risks by National Organizations and Provincial Source Documents

\begin{tabular}{|c|c|c|c|c|c|c|c|c|c|c|c|c|c|c|}
\hline \multirow{2}{*}{$\begin{array}{l}\text { Physical Risks } \\
\text { Local risks (Injection site) }\end{array}$} & \multicolumn{14}{|c|}{ PROVINCES } \\
\hline & MFC & NACI & SOGC & MAC & $\mathrm{BC}$ & $\mathrm{AB}$ & SK & MB & ON & $\mathrm{QC}$ & $\mathrm{NL}$ & NB & NS & $\overline{\mathrm{PE}}$ \\
\hline Erythema (redness) & $\mathrm{x}$ & $\mathrm{x}$ & & & $\mathrm{x}$ & $\mathrm{x}$ & $\mathrm{x}$ & $\mathrm{x}$ & $\mathrm{x}$ & $\mathrm{x}$ & $\mathrm{x}$ & $\mathrm{x}$ & $\mathrm{x}$ & $\mathrm{x}$ \\
\hline Pain & $\mathrm{x}$ & $\mathrm{x}$ & * & & $\mathrm{x}$ & $\mathrm{x}$ & $\mathrm{x}$ & $\mathrm{x}$ & $\mathrm{x}$ & $\mathrm{x}$ & $\mathrm{x}$ & $\mathrm{x}$ & $\mathrm{x}$ & \\
\hline Pruritus (itchiness) & $\mathrm{x}$ & $\mathrm{x}$ & & & & $\mathrm{x}$ & & $\mathrm{x}$ & & & & $\mathrm{x}$ & $\mathrm{x}$ & $\mathrm{x}$ \\
\hline Swelling & $\mathrm{x}$ & $\mathrm{x}$ & * & & $\mathrm{x}$ & $\mathrm{x}$ & $\mathrm{x}$ & $\mathrm{x}$ & $\mathrm{x}$ & $\mathrm{x}$ & $\mathrm{x}$ & $\mathrm{x}$ & $\mathrm{x}$ & $\mathrm{x}$ \\
\hline \multicolumn{15}{|l|}{ Minor Systemic Risks } \\
\hline Back Pain & & & & $\mathrm{x}$ & & & & & & & & & & \\
\hline Diarrhea & $\dagger$ & $\mathrm{x}$ & & & & & & & & & & & & \\
\hline Dizziness & $\mathrm{x}$ & $\mathrm{x}$ & & & & $\mathrm{x}$ & $* *$ & $\mathrm{x}$ & $\mathrm{x}$ & $\mathrm{x}$ & & $\mathrm{x}$ & $\mathrm{x}$ & $\mathrm{x}$ \\
\hline Headache & $\mathrm{x}$ & * & & $\mathrm{x}$ & $\mathrm{x}$ & $\mathrm{x}$ & & $\mathrm{x}$ & $\mathrm{x}$ & $\mathrm{x}$ & & $\mathrm{x}$ & $\mathrm{x}$ & $\mathrm{x}$ \\
\hline Facial edema & & & & & $* *$ & & & & $* * *$ & & & & & \\
\hline Fatigue & & * & & & & & $* *$ & & & & & & & \\
\hline Fever & $\mathrm{x}$ & $\mathrm{x}$ & & ++ & $\mathrm{x}$ & $\mathrm{x}$ & $\mathrm{x}$ & $\mathrm{x}$ & $\mathrm{x}$ & $\mathrm{x}$ & $\mathrm{x}$ & $\mathrm{x}$ & $\mathrm{x}$ & $\mathrm{x}$ \\
\hline Gastroenteritis & $\mathrm{x}$ & ฯ & & & & & & & & & & & & \\
\hline Hypokinesia & & & & $\mathrm{x}$ & & & & & & & & & & \\
\hline Lymphadenopathy & $\mathrm{x}$ & & & & & & & $\mathrm{x}$ & & & & & & \\
\hline Mild paralysis & & & & $\mathrm{x}$ & & & & & & & & & & \\
\hline Physical Risks & \multicolumn{3}{|c|}{ PROVINCES } & & & & & & & & & & & \\
\hline Minor Systemic Risks & MFC & NACI & SOGC & MAC & $\mathrm{BC}$ & $\mathrm{AB}$ & SK & $\mathrm{MB}$ & $\mathrm{ON}$ & $\mathrm{QC}$ & $\mathrm{NL}$ & NB & NS & $\mathrm{PE}$ \\
\hline Myalgia & $\mathrm{x}$ & & & & & & $* *$ & & & & & & & \\
\hline Nausea & $\mathrm{x}$ & $\mathrm{x}$ & & & & $\mathrm{x}$ & ** & $\mathrm{x}$ & $\mathrm{x}$ & & & $\mathrm{x}$ & $\mathrm{x}$ & $\mathrm{x}$ \\
\hline Neck ache & & & & $\mathrm{x}$ & & & & & & & & & & \\
\hline Vomiting & $\mathrm{x}$ & & & & & $\mathrm{x}$ & & $\mathrm{x}$ & & & & $\mathrm{x}$ & & \\
\hline Major Systemic Risks & & & & & & & & & & & & & & \\
\hline Anaphylaxis (as with any vaccine) & & + & & & ** & ** & & $* *$ & & & & $* *$ & & $* *$ \\
\hline Serious/severe allergic reaction & & & & & *** & $* *$ & ** & & $* *$ & $* *$ & & $* *$ & & \\
\hline Bronchospasm & $\mathrm{x}$ & ब & & & $* *$ & $* *$ & & $* *$ & $* *$ & & & & & \\
\hline Convulsions & & & & $\mathrm{x}$ & & & & & & & & & & \\
\hline Death & & & & $\mathrm{x}$ & & & & & & & & & & \\
\hline Hypertension & & $\mathrm{x}$ & & & & & & & & & & & & \\
\hline Syncope (fainting) & $\mathrm{x}$ & & & $\mathrm{x}$ & & $\mathrm{x}$ & & $\mathrm{x}$ & & & & & & \\
\hline Unknown potential risks & & & & $\mathrm{x}$ & & & & & & & & & & \\
\hline Vaginal bleeding & & II & & & & & & & & & & & & \\
\hline
\end{tabular}

Note. $\mathrm{MFC}=$ Merck Frosst Canada; NACI = National Advisory Committee on Immunization;

SOGC $=$ Society of Obstetricians and Gynecologists of Canada; MAC = MacLean's Magazine

Symbols: $\mathrm{x}$ denotes identified or implied risk due to vaccine;

+ denotes silence on anaphylaxis: "There was no evidence that vaccination resulted in allergic reactions or other immunemediated diseases" (National Advisory Committee on Immunization, 2007);

${ }^{++}$denotes that fever was severe and led to delirium in the subject (Gulli, 2007);

* denotes that subjects reporting a serious adverse event were similar in the vaccine and placebo groups, as were the types of serious adverse event reported.

"denotes that physical risk is "probably" related to vaccine;

"denotes that physical risk is possibly related to vaccine;

*** denotes that physical risk is rare;

${ }^{\dagger}$ denotes that physical risk in females receiving placebo were higher than rates in vaccine recipients, $1.5 \%$ vs. $1.2 \%$

World Health Organization (WHO) Adverse Reaction Terminology (2005) was used for the risk categories.

cine-related risk (with only one noting it was rare). Words such as "occasionally," "less commonly," "seldom," "infrequently," and "less typically" were also found in many provincial documents without qualifiers as to what these words meant (i.e., one in 10 or one in 1,000 or one in 100,000 etc.). In another example, NACI lists headache/hypertension as "definitely related" (NACI, 2007) yet none of the provinces included hypertension as a risk (Table 2).

An overall summary of the differences in the list of physical risks (local, minor systemic, or major systemic) by each of the ten provinces, in 
TABLE 3. Comparison of HPV Vaccine-related Physical Risk by Provinces and Other Organizations with NACI

\begin{tabular}{|c|c|c|c|c|}
\hline Provinces & $\begin{array}{c}\text { Local } \\
\text { risks } \\
(4)\end{array}$ & $\begin{array}{l}\text { Minor } \\
\text { systemic } \\
\text { risks (6) }\end{array}$ & $\begin{array}{c}\text { Major } \\
\text { systemic } \\
\text { risks (3) }\end{array}$ & $\begin{array}{c}\text { Total } \\
\# \\
\text { of } \\
\text { risks } \\
(13)\end{array}$ \\
\hline $\begin{array}{l}\text { British } \\
\text { Columbia }\end{array}$ & 3 & 3 & 3 & 9 \\
\hline Alberta & 4 & 5 & 4 & 14 \\
\hline Saskatchewan & 3 & 5 & 1 & 9 \\
\hline Manitoba & 4 & 6 & 5 & 15 \\
\hline Ontario & 3 & 5 & 4 & 12 \\
\hline Quebec & 3 & 2 & 1 & 6 \\
\hline Newfoundland & 3 & 1 & $\mathrm{O}$ & 4 \\
\hline $\begin{array}{l}\text { New } \\
\text { Brunswick }\end{array}$ & 4 & 5 & 2 & 11 \\
\hline Nova Scotia & 4 & 4 & o & 8 \\
\hline $\begin{array}{l}\text { Prince } \\
\text { Edward } \\
\text { Island }\end{array}$ & 3 & 4 & 1 & 8 \\
\hline \multicolumn{5}{|c|}{$\begin{array}{l}\text { Other organizations } \\
\text { MFC }\end{array}$} \\
\hline SOGC & 3 & $\mathrm{O}$ & o & 3 \\
\hline MAC & O & 6 & 4 & 10 \\
\hline
\end{tabular}

Note. (), the number of physical risks identified by NACI. * One of these risks is probably related (i.e., vaginal bleeding) and one risk is possibly related (i.e., bronchospasm).

comparison to the number of risks cited by NACI, is shown in Table 3.

\section{Discussion}

The objective of this study was to conduct a comprehensive, systematic review of school-based HPV vaccine documents available to parents, legal guardians, and girls in Canada in preparation for consent/authorization to assess the accuracy, completeness, and consistency of information about vaccine-related physical risks when compared with information provided by: the manufacturer, Merck Frosst Canada; NACI; SOGC, and popular media (the Gulli article in Maclean's magazine in 2007). We used NACI as our reference because they are mandated by the PHAC to set the national standards for vaccine use from which provincial and territorial governments make subsequent recommendations. To the best of our knowledge, no such systematic review has been done of physical risks listed in school-based HPV vaccine (or other vaccines) consent information documents in Canada or anywhere else in the world. For example, a recent systematic review on strategies for implementing school-based influenza vaccination programs for children was silent on issues around completeness, and consistency of vaccine physical risk disclosure upon which to base consent in this setting (Cawley et al. 2010).

There are some limitations to this study. Despite our aggressive efforts to retrieve HPV vaccine-related information for this review from all provincial and territorial jurisdictions in Canada, it is possible that information was missed. This study examined how materials developed by each province differed from each other and from the NACI-developed guidance. Furthermore, since the data collection was completed, HPV vaccine information for parents, legal guardians, and girls may have been modified or supplemented in one or more of the 10 provinces where documents were retrieved. With these caveats in mind, this review found that a wide variety of documents were used across Canada to share information about HPV vaccination (e.g., pamphlets, fact sheets, FAQs, and brochures).There are risks and benefits in having more than one type and source of information. Some may be more effective in reaching different target populations, but many documents can create confusion if information is not clear and consistent.

This review found important discrepancies in the accuracy, completeness, and consistency of information disclosed about HPV vaccine-related physical risks, with respect to both the nature and probability of risks. These discrepancies have a significant effect on the legal validity of the consent/ authorization process.

First, for there to be a legally valid consent, all material risks must be disclosed in the consent, it must be free and informed and made by a competent individual with decision-making authority. To be properly informed in relation to risks, the person from whom consent is sought must be told of the following:

- the nature of the intervention and its gravity

- all material risks (including probability and gravity, grave consequences even if they have a low probability, and what the doctor knows or should know the patient deems relevant)

- any special or unusual risks 
- any alternatives (including doing nothing) and their risks

- answers to any questions posed by that person (Peppin, 2007)

On the basis of Table 2, one can reasonably ask which, if any, of the ten provinces were getting valid consents given the variation in risks presented compared to those cited in the NACI evidence-based review of HPV vaccine. This is a matter of concern as NACI is mandated to set the national standard on vaccine use (National Advisory Committee on Immunization, 2009) including the provision of statements on vaccine risks and benefits. NACI uses technical language and scientific format and reasoning in its statements on vaccines. For example, it uses phrases such as "probably related" and "possibly related", terms used by the WHO in causality assessment and subtleties understood by professionals but likely not by the general public (World Health Organization, 2011). Provincial authorities have the difficult task of translating this information into plain language for the general public. This may explain some of the discrepancies noted between the risks cited by NACI and those cited by each of the ten provinces. Regardless, these discrepancies can lead to confusion among health care providers and the public. Clarity of language for the public is a crucial element as the Internet now provides wide public access to technical documents such NACI statements and manufacturers' product monographs, each with language that may be confusing to the general public (MacDonald \& Picard, 2009). This study demonstrates the inconsistent translation of technical language into plain language for the public.

Second, since parents, legal guardians, and girls could easily access web-based HPV vaccine -related information from different provincial jurisdictions and other Canadian authorities, having different (and sometimes contradictory) information about HPV vaccine-related physical risks could lead to confusion; "which is right?" Moreover, inconsistencies across jurisdictions and authoritative sources may fuel distrust in vaccination initiatives and undermine confidence in provincial vaccine programs; "What are they hiding and why? What are they not telling us?" It is noteworthy that in one of the ten provinces in Canada (British Columbia) with a school-based HPV program, a recent survey of parents who chose not to have their daughters immunized in the school-based HPV vaccine program cited concerns about vaccine safety and insufficient information as reasons for their decision (Ogilvie, Anderson, Marra, McNeil, Pielak, Dawar, and McIvor, 2010).

To avoid these potential negative consequences, audience-appropriate, accurate, complete, and consistent HPV vaccine documents should be available for use across the country and perhaps even between countries. Within Canada, such documents could be developed in a collaborative and integrated manner so that all provinces and territories, especially smaller ones with limited resources, could benefit from sharing knowledge, templates, and experience about required content for optimal disclosure for informed consent/authorization in school-based vaccine programs such as those for HPV. Such integration could help to reduce public confusion and to increase trust in school-based vaccine programs. Furthermore, by collaborating on the development of documents that inform the consent/authorization process, savings in human and financial resources could be used to develop additional documents tailored to meet the needs of discrete target populations (e.g., different age, cultural, and linguistic groups) in each jurisdiction. Most importantly, however, collaboration and integration among the provinces and territories could help to ensure that all school-based HPV vaccine programs meet ethical and legal requirements for valid informed consent/authorization.

Given the composition and mandate of NACI, it appears to be well-placed to be the primary contributor to the development of audience-appropriate, accurate, complete, and consistent HPV vaccine documents that clearly and authoritatively define the physical risks. NACI is the Canadian immunization technical advisory group that should do this, as recommended by the WHO (Nelson, Gessner, DeRoeck, \& Duclos, 2010) as it is the most authoritative organization for this task in Canada. The committee members come from across Canada, are independent, and the committee has the breadth of technical expertise as well as access to data in both the public domain and manufacturers' proprietary data needed to define these risks. The important step of translating NACI scientific language into plain language for the public could be undertaken by plain language experts, and then made available to all jurisdictions in Canada. This would require additional support from PHAC as NACI members do not 
necessarily have specific expertise in public communication, plain language requirements, or in the development of templates for information sheets and consent/authorization forms for the general public. A national risk communication committee constituted with all of the relevant areas of expertisevaccinology, communication, ethics, law, and health education would be needed to accomplish this to expeditiously develop the needed audience-appropriate, accurate, complete, and consistent documents required for the consent/authorization process. This committee would be well advised to use an established standardized risk classification scheme, such as the WHO adverse reaction terminology or the Brighton Collaboration (Kohl et al., 2005) adverse event terminology (if the term has been reviewed), or to develop such a scheme to promote accuracy, completeness, consistency, and clarity across documents. The committee's documents should be published by PHAC and could also be included as appendices to each specific NACI statement on vaccine use and would be especially pertinent for school-based vaccination programs. The provinces and territories could then, in a coordinated fashion, adapt these templates to their jurisdictional particularities (although ongoing co-ordination would be essential to prevent the dissemination of inaccurate, incomplete, and/or inconsistent information). The development of a national committee for risk communication documents might also provide a model to improve accuracy, completeness, and consistency of vaccine risk documents in other countries.

This review of available Canadian provincial school-based HPV vaccine program documents demonstrates the failure of the current regionally idiosyncratic and independent approach to providing audience-appropriate, accurate, complete, and consistent information for all Canadians. This failure is particularly concerning in the context of school-based vaccine programs where the information is primarily provided in written form with very limited opportunity for discussion. Ideally the ten provinces, three territories, and national health authorities could work more closely together to develop written documents that will provide parents, legal guardians, and students with appropriate vaccine risk and benefit information. This will help ensure that valid consents/authorizations are obtained, especially for school-based vaccine programs such as HPV. Furthermore, having accurate, complete, and consistent vaccine-related information would help the general public make a better informed decision regarding immunizations especially when confronted by controversial magazine articles such as that written by Gulli (2007), that may not specifically disclose all the physical risks and benefits associated with the HPV vaccine.

Given that many countries are now considering wider use of influenza vaccine, including schoolbased programs (Cawley et al., 2010) there is international relevance for the points raised in this review concerning accuracy, completeness, and consistency of information for decision makers who are not present at the time of vaccination. Thus, other countries may also do well to assess the accuracy, completeness, and consistency with respect to physical risks in documents they use to inform the consent/authorization process (particularly in school-based programs) across their countries.

For all vaccine programs in Canada and abroad, clear vaccine risk and benefit disclosure is recommended to avoid confusion, promote the integrity of the consent/authorization process, and build trust in the vaccine program and the vaccine itself. Further research initiatives that help clarify vaccine risk language into best practice guidelines to help ensure that accurate, complete and consistent consent/ authorization forms are available for school-based immunization programs are warranted.

\section{Acknowledgment}

Funding for the research assistant was provided through an unrestricted grant from the Dalhousie Medical Research Foundation.

\section{References}

Bekkers, R.L., Massuger, L.F., Bulten, J., \& Melchers, W.J. (2004). Epidemiological and clinical aspects of human papillomavirus detection in the prevention of cervical cancer. Reviews in Medical Virology, 14(2), 95-105.

Cawley, J., Hull, H.F., \& Rousculp, M.D. (2010). Strategies for implementing school-located influenza vaccination of children: a systematic literature review. Journal of Scholarly Health, 8o, 167-175.

Department of Finance Canada. (2007). The Budget Plan, No. F1-23/2007-3E (p. 96). Retrieved 
from http://www.budget.gc.ca/2007/pdf/bp 2007e.pdf

Gardasil $^{\mathrm{TM}}$. (2008).Quadrivalent Human Papillomavirus (Types 6, 11, 16, 18) Recombinant Vaccine [Monograph].

Gulli, C.. (2007). Our girls are not guinea pigs. Maclean's Magazine. Retrieved from www. macleans.ca/science/health/article.jsp?content= 20070827_108312_108312

Health Canada. (2009). Healthy Living. Retrieved from http://www.hc-sc.gc.ca/hl-vs/iyh-vsv/ diseases maladies/hpv-vph-eng.php

Health Canada. (2007). Summary Basis of Decision: Gardasil $^{\mathrm{TM}}$. Retrieved from http://www. hc-sc.gc.ca/dhp-mps/prodpharma/sbd-smd/ phase1-decision/drug-med/sbd_smd_2007_ gardasil_102682-eng.php

Hitwise: [Home page on internet]. Retrieved from http://www.hitwise.com/us/datacenter/main/ dashboard-10133.html

Kohl, K.S., Bonhoeffer, J., Braun, M.B., Chen, R.T., Duclos, P., Heijbel, H., \& Marcy, M.. (2005). And The Brighton Collaboration. Creating a Global Standard for Case Definitions (and Guidelines) for Adverse Events Following Immunization. In: K. Henriksen, J. B. Battles \& E. S. Marks, et al., (Eds.),. Advances in Patient Safety: From Research to Implementation (Vol. 2: Concepts and Methodology). Rockville, MD: Agency for Healthcare Research and Quality; AHRQ Publication No. 05-0021-2, Feb 2005.

Lenselink, C.H., Melchers, J.G., Quint, W.G., Hoebers, A.M., Hendriks, J.C., Massuger, L.F., \& Bekkers, R.L.. (2009). Sexual Behaviour and HPV Infections in 18 to 29 Year Old Women in the Pre-Vaccine Era in the Netherlands. Retrieved from http://www.plosone.org/article/info:doi\% 2F10.1371\%2Fjournal.pone.0003743

Lippman, A., Melnychuk, R., Shimmin, C., \& Boscoe, M. (2007). Human papillomavirus, vaccines and women's health: questions and cautions. Canadian Medical Association Journal, 177, 484-487.

MacDonald, N.E., \& Picard, A. (2009). A plea for clear language. CMAJ 2009, 180, 697-698.

MacDonald, N., Stanbrook, M.B., \& Hébert, P.C. (2008). Human papillomavirus vaccine risk and reality. Canadian Medical Association Journal, 179, 503.

National Advisory Committee on Immunization. (2009). Evidence-based recommendations for immunization - Methods of the National Advisory Committee on Immunization. Cana- dian Communicable Disease Report, 35 (ACS-1):1-10. Retrieved from http://www. phac-aspc.gc.ca/publicat/ccdr-rmtc/o9vol35/ acs-1/index-eng.php

National Advisory Committee on Immunization. (2007). Statement on human papillomavirus vaccine. Canadian Communicable Disease Report, 33 (ACS-2):1-31. Retrieved from http://www.phac-aspc.gc.ca/publicat/ccdr-rmtc/ o7pdf/acs33-02.pdf

National Cancer Institute. (2009). Human Papilloma viruses and Cancer: Questions and Answers. Retrieved from http://www.cancer. gov/cancertopics/factsheet/Risk/HPV

Nelson, A., Gessner, B., DeRoeck, D., \& Duclos, P. (2010). The Role of National Advisory Committees in Supporting Evidence-Based Decision Making for National Immunisation Programs. Vaccine 28(Suppl. 1): A1-A110.

Ogilvie, G., Anderson, M., Marra, F., McNeil, S., Pielak, K., Dawar, M., \& McIvor, M.. (2010). A population -based evaluation of a publically funded school-based HPV vaccine program in British Columbia, Canada: Parental factors associated with HPV vaccine receipt. Retrieved from http://www.ncbi.nlm.nih.gov/ pmc/articles/PMC2864299/?tool=pubmed.

Patrick, D.M., Bigham, M., Ng, H., White, R., Tweed, A., \& Skowronski, D.M.. (2003). Elimination of acute hepatitis B among adolescents after one decade of an immunization program targeting grade 6 students. Pediatrics Infectious Diseases, 22, 874-877.

Peppin, P. (2007). Informed consent Canadian health law and policy. In J. Downie, T. Caulfield \& C. M. Floor (Eds.), Canadian health law and policy (3rd ed.). Markham, ON: LexisNexis.

Priest, A. (2006). Cervical cancer vaccine may come soon to Canada. Canadian Medical Association Journal, 175, 235.

Shier, M., \& Bryson, P. (2007). SOGC Clinical Practice Guidelines: Canadian Consensus Guidelines on Human Papillomavirus, Chapter 8: Vaccines. Journal of Obstetrics and Gynaecology Canada 196, s51-s54.

World Health Organization. (2005). WHO Adverse Reaction Terminology. The Uppsala Monitoring Centre. Uppsala, Sweden.

World Health Organization. (2011). Aide Memoire. Adverse Events following Immunization (AEFI): Causality. Geneva, World Health Organization. Retrieved from http://www.who.int/ vaccines-documents/DocsPDFo5/815.pdf. 